\title{
ACADEMIC DETAILING: METHODS AND SUCCESS STORIES IN IPA-MODEL HMOS
}

What causes physicians' practice patterns to change? This is of particular importance today, because a fundamental goal of the emerging managed care paradigm ${ }^{1}$ is not only to influence the cost of health care, but also the patient's health status and quality of life. Both under-use and over-use of pharmacotherapy can result in poor patient outcomes as well as increased costs. Avorn and Soumerai ${ }^{2}$ have found that, in the ambulatory setting, inappropriate prescribing decisions result in under use of effective agents for treatable diseases. By influencing physician prescribing practices, Avorn and Soumerai have proven enhancements in safety, therapeutic effectiveness, and resource utilization.

Relevant outcomes include drug effectiveness, side effects, and cost. A prescriber's choice of agent will be influenced by therapeutic outcomes (either perceived or measured). The physician's belief in the outcome (i.e., anecdotal evidence) and the outcome's probability (i.e., published scientific experience) together form a justification for prescribing a particular drug. ${ }^{3}$ The prescriber's confidence in his ability to accomplish a task (i.e., change a patient's therapy successfully) and perception of how much control he or she has over the decision also influence the adoption of a treatment modality.

Some authors believe physicians' prescribing patterns are mainly influenced by the scientific literature, but commercial sources of information-such as advertisements, and interactions with pharmaceutical industry detail personnel-play a major role, ${ }^{7.5}$ as do awareness and peer influence. ${ }^{2}$ Ideally, dissemination of information through published medical research and their presentation in continuing education programs would lead to changes in prescribing behavior. However, the roots of behavior change lie deep within each physician's underlying personality traits and knowledge, combined with fear of malpractice, societal concerns of cost and outcome, patients' perceived and real demands, and financial incentives. ${ }^{6}$ Clearly, changing prescribing behavior is more difficult than transmitting information. ${ }^{3}$

Academic detailing programs are tools for improving the appropriateness and costeffectiveness of medication prescribing. The overriding principle is to provide physicians with up-to-date, evidence-based information to encourage the use of optimal drug therapy. This provision of information has the objective of achieving the best patient outcomes in the most cost-effective manner. Academic detailing should be proactive, educational; and non- punitive in nature; it should reinforce positive changes in prescribing behavior.

The two case studies described briefly in this article demonstrate how we approached separate therapeutic categories with some or all of the above objectives in mind. The ACE inhibitors case simply focuses on achieving cost savings through therapeutic interchange between agents with similar expected outcomes but considerably different costs. The HMG CoA reductase inhibitor case looks at improving patient outcomes through proper drug therapy, monitoring for safety, and providing care in the most cost-effective manner possible. A detailed description of each intervention follows a review of the literature.

\section{ACADEMIC DETAILING: COMPONENTS DESCRIBED PREVIOUSLY}

The merits of face-to-face provider education, or academic detailing, have been well documented ${ }^{6.7}$

Avorn and Soumerai ${ }^{2}$ described the ideal academic detailing program as one that: $\Delta$ Focuses programs on specific categories of physicians as well as their opinion leaders

A Stimulates active physician participation in educational interactions

A Uses concise educational materials
$\Delta$ Provides objective, unbiased, up-to-date information

$\Delta$ Uses clinical pharmacists to provide two-way, face-toface communication with physicians

A Highlights and repeats essential messages

$\Delta$ Includes specific recommendations for alternative treatments

$\Delta$ Provides positive reinforcement to improved practices at follow-up visits

In a review of studies that document the use of nonregulatory measures to improve physician performance, Soumerai et al. ${ }^{8}$ summarized the effectiveness of different strategies in changing prescription decision making. Mailing educational materials and providing computerized drug-use profiles of individual patients alone did not affect prescribing habits. Simple "secretarial reminders," such as computerized messages, were effective when they solved errors of omission rather when they tried to correct physician beliefs. One-on-one outreach visits by either clinical pharmacists or physicians were responsible for practical and clinical improvements in prescribing patterns.

Davis et al. ${ }^{9}$ performed a meta-analysis of 102 trials of interventions designed to assist health care professionals in providing services more effectively and efficiently. Educational interventions includ- 
ed the following:

$\Delta$ Educational materials

$\Delta$ Continuing medical education programs

A Outreach visits including academic detailing and/or counterdetailing

A Local opinion leaders or educational influentials

$\Delta$ Patient-mediated interventions (patient education materials)

$\Delta$ Audit with feedback

$\Delta$ Reminders

Of 160 separate interventions, 99 interventions (62\%) showed an improvement in at least one major outcome in physician performance or health care; 53 (33\%) failed to demonstrate improvement. Multifaceted interventions (using three or more educational strategies) were proven more effective ( $79 \%$ positive) in changing health care outcome, as compared with the two-method and the single-method interventions ( $64 \%$ and $60 \%$ positive, respectively). Fox et al. ${ }^{10}$ also supported multifaceted interventions, stating that learning and change take place through a series of "impactors."

According to Green et al., "1 the most successful interventions for changing performance and health care outcomes are those using the following"

$\Delta$ Office facilitators

$\Delta$ Patient education

$\Delta$ Reinforcement methods (feedback or reminders)

A Predisposing or disseminating strategies

In a pilot program of 20 physicians and 15,000 pa- tients, Miller ${ }^{12}$ demonstrated a $6.2 \%$ decrease and a $17.3 \%$ decrease in per-member permonth costs in a mixed commercial and Medicare-risk program, respectively. This program utilized the following components:

A Graphic prescriber report cards

A Chart reviews

A One-on-one visits between clinical pharmacists and physicians

A Therapeutic conversion protocols

\section{ADDITIONAL SUGGESTED PROGRAM COMPONENTS}

Through experience and review of published material, we include the following elements in an academic-detailing campaigns for our IPAmodel HMOs.

1. Introductory correspondence on program from medical director and/or pharmacy director

2. Identification of target therapeutic areas

3. Identification of literaturebased, preferred treatment option(s)

4. Analysis and trending of providers with patients falling outside preset clinical parameters

5. Educational letter to relevant physicians with patient profiles

6. Response card with educational letter asking for feedback and determining whether further follow-up is required

7. Follow-up telephone appointments and office ap- pointments (with providers ranking highest in patient-care improvement opportunities) 8. Providing these materials during visits: Handout or newsletter (one to two pages; colorful; graphic); summary slides (10-15) highlighting essential messages and criteria (laptop computer detailing or hard copy slides); patient profiles with adequate detail; and supporting references and literature articles.

9. Measurement and tracking of results, such as those that

(a) monitor changes in key indicators over time (e.g., therapeutic class PMPM, product market share, therapeutic class cost /prescriptions, patient and physician specific tracking) and (b) analyze physician-specific product conversion or other therapy changes.

In addition to these program elements, we have also begun to use follow-up comarketing efforts with partnering pharmaceutical companies. This additional reminder system was used in our HMG CoA reductase inhibitors case.

Of the above components, we believe the most critical ones are the patientspecific profiles and face-toface conversations with the prescribing physician. In addition, another major factor in our success has been with repetitive interventions-the same message delivered to selected providers in several different ways. Finally, as an overall program theme, we view our role as one of improving physicians' aware- ness of evidence-based, clinically appropriate, cost-effective drug therapy. Therefore, our messages are informational and nonthreatening. Hence, they are viewed by physicians as the tools to make the best drug therapy decisions.

\section{CASE STUDY 1: ACE INHIBITORS}

Using this intervention strategy, WellPoint Pharmacy Management implemented an ACE inhibitor conversion academic detailing program at a 200,000-member IPA HMO in December 1994. The campaign focused on converting plan members who had received Vasotec (enalapril), Capoten (captopril), or Prinivil (lisinopril) to Accupril (quinapril), Zestril (lisinopril), Monopril (fosinopril), Altace (ramipril), or Lotensin (benazepril).

\section{Methods}

Claims files were reviewed for third quarter 1994 to identify those members affected. A total of 479 letters were mailed to physicians in December 1994. An additional letter was sent to these same physicians in April 1995 to correct identified claim reporting errors. In addition, to ensure data validity, 29,000-member months (and the claims associated with those member months) were not included in the fourth quarter 1994 claim data because of the attrition of these members before the measurement period of sec- 
Table 1. ACE Inhibitor Patient Conversion Analysis

\begin{tabular}{lc}
\hline Time Period & Total Patients Converted \\
\hline Third quarter 1994 versus first quarter 1995 & 146 \\
New patient starts on preferred agents & $57.2 \%$ \\
first quarter 1995 &
\end{tabular}

ond quarter 1995. Finally, members joining the plan after the intervention began were not included in the study.

A total of 84 provider responses were received from the enclosed reply cards (a response rate of $18 \%$ ), of which 79 were positive and 5 were negative. Individual interventions were completed using three methods of provider contact: telephone calls, written correspondence, and office visits.

Patient conversions were tracked from fourth quarter 1994 through first quarter 1995. Table 1 demonstrates that there were 146 actual conversions from nonpreferred agents to preferred agents. In addition, Figures 1 and 2 demonstrate that, by shifting use to more cost-effective agents, a cost savings of $\$ 56,124$ in savings per quarter was realized by the HMO.

\section{CASE STUDY 2: HMG COA REDUCTASE INHIBITORS}

Using the same type of intervention method as the ACE inhibitor case study, WellPoint Pharmacy Management implemented an HMG CoA reductase inhibitor academic detailing program in October 1995 for the same 200,000 member HMO. The focus of this program was twofold; it differs from the study reported in the March/April 1996 Journal of Managed Care Pharmacy by Baran et 'al. ${ }^{13}$

The primary objective of our study was to raise provider awareness of recent literature regarding secondary prevention for hyperlipidemia and how drug therapy with HMG CoA reductase inhibitors can slow the progression of atherosclerosis and reduce the incidence of cardiovascular events. The number of patients treated for hyperlipidemia based on LDL levels and risk,status using the 1993 National Cholesterol Education Program Guidelines ${ }^{14}$ was therefore expected to increase as a result of this intervention with the intention of reducing cardiovascular morbidity and mortality within the HMO population.

In addition, the campaign sought to promote the use of the most cost-effective HMG CoA reductase in-

hibitors and decrease the use of the health plan's nonpreferred HMG CoA reductase inhibitor, lovastatin (Mevacor). Safety was also advocated with physicians selected for face-to-face visits by recommending appropriate liver-function monitoring. A total of 365 physicians received the intervention letter in addition to 40 follow-up detailing visits (Table 2 ). Once our

Figure 1. ACE inhibitor case study use analysis of second and third quarter 1994 versus first and second quarter 1995.

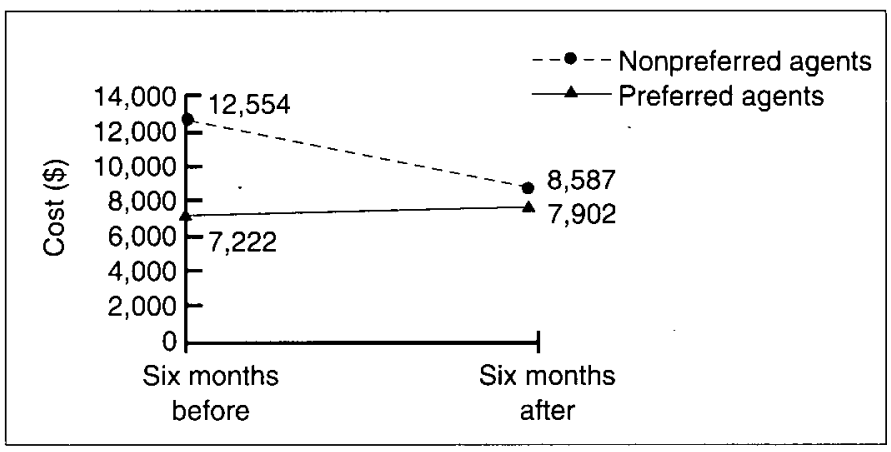

Figure 2. ACE inhibitor ingredient costs (second and third quarter 1994 versus first and second quarter 1995)

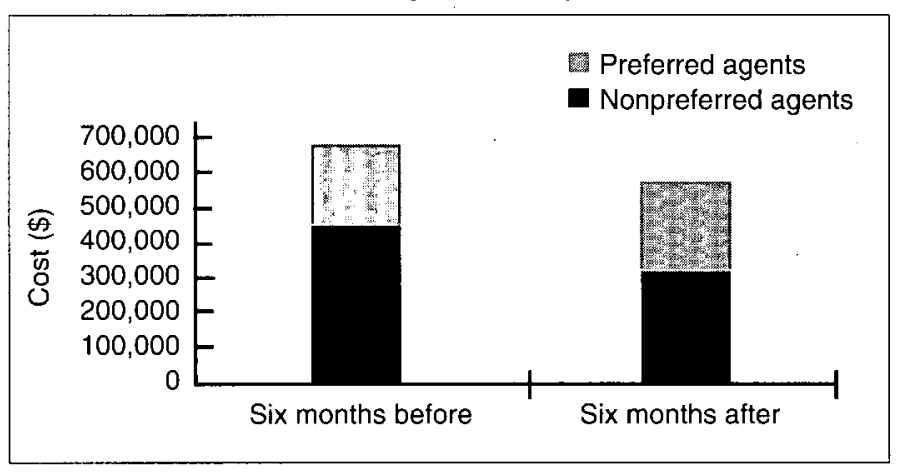

clinical pharmacist detailing was completed, reminder detailing using a mutually agreed upon detail aid was implemented with one partnering drug company.

The results of this program are shown in Tables 3 and 4. A total of 72 patients were converted between the third quarter 1995 and the first quarter 1996. Additionally, $70 \%$ of new patients beginning therapy in the first quarter of 1996 received preferred therapy.

The results of this case study clearly indicate an increase in the number of patients being treated for hyperlipidemia (Table 3), as well as an increase in the use of more cost-effective agents (Table 4). The study objectives were met.

We attribute the successful results of these programs primarily to the following basic principles:

A Clinical staff involvement

A Sound claims data to translate into useful information

A Supportive, informative and repetitive feedback to physicians

A Appropriate tracking, measurement, and follow-up

\section{STUDY LIMITATIONS}

Although tracking and measurement methods have not been perfected or statistically validated, they indicate that academic detailing is an evolving science and that both clinical and economic changes in practice patterns can be achieved with nonpunitive efforts. We did not have access to medical chart

Continued on page 593 
Table 2. HMG CoA Reductase Inhibitor detailing program Intervention Summary

\section{Intervention Description}

HMG COA letter to physicians pre

scribing Mevacor to encourage use

of more cost-effective formulary agents

Total responses to HMG CoA letter

No positive responses

Follow-up academic detailing visits

Quantity in Fourth Quarter 1995

365

$36(10 \%)$

$34(94 \%)$

40

Table 3. HMG CoA Reductase Inhibitor Use Analysis

\begin{tabular}{lccc}
\hline & \multicolumn{3}{c}{ No. Claims } \\
\cline { 2 - 4 } Drug & $\begin{array}{c}\text { Third Quarter } \\
\mathbf{1 9 9 5}\end{array}$ & $\begin{array}{c}\text { First Quarter } \\
\mathbf{1 9 9 6}\end{array}$ & $\begin{array}{c}\text { \% } \\
\text { Increase }\end{array}$ \\
\hline Mevacor & & & \\
$\quad$ (nonpreferred) & 2,348 & 2,224 & -5 \\
Lescol (preferred) & 840 & 1,330 & 58 \\
Zocor (preferred) & 1,100 & 1,872 & 70 \\
Pravachol (preferred) & 1,914 & 2,430 & 27 \\
Total & 6,202 & 7,856 & 27 \\
& & & \\
\hline
\end{tabular}

or ICD-9/CPT-4 data; there-

tality) and total health care

fore, our results and conclucosts. We did not use a con-

sions are based solely on drug therapy changes as opposed to measured patient care outcomes (e.g., cardiovascular morbidity and mor-

trol group in either study, which limits our ability to determine whether prescribing changes measured resulted from the intervention or oth-

Table 4. HMG CoA Reductase Inhibitor Market Share Analyses

\begin{tabular}{lcc}
\hline & \multicolumn{2}{c}{$\%$ Market Share } \\
\cline { 2 - 3 } Drug & Third Quarter 1995 & First Quarter 1996 \\
\hline Mevacor & 38 & 28 \\
Preferred & 62 & 72
\end{tabular}

er market forces (e.g., the release of various secondary prevention trials in hyperlipidemia, direct-to-consumer advertising, continuing medical education). The results of our own intervention letter and follow-up detailing are difficult to separate from the detailing of our partnering drug company. In future interventions, we plan to add a control group to our method to assist in elucidating results.

\section{CONCLUSION}

An effective academicdetailing program reduces drug therapy costs in IPAmodel HMOs. In addition, others have demonstrated that such programs can also improve drug prescribing through enhancing safety and therapeutic effectiveness. ${ }^{2}$ By tracking our hyperlipidemia program, we hope to take this one step further and show that patient outcomes can also be improved through interventions that improved pharmacotherapy.

Brian Sweet, B.S. Pharm., M.B.A. Regional Pharmacy Director

Sheetal Patel, B.S. Pharm. Clinical Pharmacy Administrator

WellPoint Pharmacy Management 27001 Agoura Road Calabasas Hills, CA 91301

\section{References}

1. Kaplan J. The emerging managed care paradigm: health care in transition. Med Interface 1994 Sept: 58-9

2. Avorn J, Soumerai SB. Principles of educational outreach to improve clinical decision making. JAMA 1990; 263: 549-56.

3. Larson LN, Sargent LJ. Designing provider education programs in managed health care plan. In: A pharmacist's guide to principles and practices of managed care pharmacy. Alexandria,

Virginia:Foundation for Managed Care Pharmacy, 1995.

4. Orlowski JP, Wareska L. The effects of pharmaceutical enticements on the physician prescribing patterns. Chest 1992; 102: 270-3

5. Avorn J, Chen M Hartley R. Scientific versus commercial sources of influence on the prescribing behavior of physicians. Am J Med 1982; 73 $4-8$

6. Lomas J, Anderson GM, Domnick-Pierre K, Vayda E, Enkin MW, Hannah WJ. Do practice guidelines guide practice? The effect of a consensus statement on the practice of physicians. N En- gl J Med 1989; 321: 1306-11.

7. Keys PW, Goetz CM, Keys PA, Sterchelle JA, Snedden TM, Livengood BH. Computer aided academic detailing as part of a drug benefit program. Am J Health-Syst Pharm 1995; 52:

2199-204

8. Soumerai SB, McLaughlin TJ, Avorn J. Improving drug prescribing in primary care: a critical analysis of the experimental literature. Milbank Q $1989 ; 67: 268-317$

9. Davis DA, Thomson MA, Oxman AD, Haynes RB. Changing physician performance: a systematic review of the effect of continuing medical education strategies. JAMA 1995; 274: 700 .

10. Fox RD, Mazmanian PE, Putnam RW. Changing and learning in the lives of physicians. New York: Praeger, 1989.

11. Green L, Kreuter M, Deeds S, Partridge K. Health education planning. A diagnostic approach. Palo Alto, CA: Mayfield Press, 1980. 12. Miller W. A successful field-based pharmacy program. Med Interface 1995 )Feb): 71-7. 13. Baran RW, Duchane J, Parker L, Cornwell S,
Francic D, Erwin G. Effectiveness of academic detailing in the managed care environment: improving prescribing of lipid-lowering agents. J Managed Care Pharm 1996; 2: 148-57

14. National Cholesterol Expert Panel. Report of the National Cholesterol Education Program Expert Panel on detection, evaluation, and treatment of high blood cholesterol in adults (adult treatment panel 11). JAMA 1993; 269: 3015-23.

15. Bandura A. Social foundations of thought and action: a cognitive theory. Englewood Cliffs, NJ: Prentice-Hall, 1986.

16. Goldman I. Changing physicians behavior: the pot and the kettle. N Engl J Med 1990; 322: 1524-5.

17. Szchetman, JM, Kanwal NK, Schrith WS, Elinsky EG. The effect of an education and feedback intervention on group-model and networkmodel health-maintenance organization physician prescribing behavior. Med Care 1995; 33(2): 139-44. 


\section{THE PHARMACIST CLINICIAN: PRESCRIPTIVE AUTHORITY IN NEW MEXICO}

In New Mexico, a pharmacist clinician is a registered pharmacist with advanced training in the areas of physical assessment and pharmacotherapy who practices with prescriptive authority under the supervision of a physician. The creation of the pharmacist clinician through the Pharmacist Prescriptive Authority Act (Section 6111B-3 NMSA 1978) was originally designed to address the concern of providing quality health care to the underserved rural population of New Mexico. New Mexico is the fifth largest state in land mass; however, its population is less than two million. Given the rural nature of the state, a large population suffers from lack of readily accessible health care services.

The first problem in a rural setting is a population too small to justify a full-time physician. Slightly larger communities may have an overworked physician serving a patient population too large for one physician-but too small to justify a second physician. The pharmacist clinician may act as a physician extender in both circumstances, alleviating the excessive physician workload. The second problem is that the community may not be large enough to support a pharmacy based on prescription volume alone. Pharmacist clinicians may supplement their income by providing reim- bursable patient-care services. Pharmacist clinicians practicing in communities without a physician may eliminate the need for patients to travel to receive care for minor ailments or minor adjustments in medications for chronic diseases.

Allowing pharmacists in long-term care facilities to adjust medication regimens eliminates unnecessary physician visits, delays in refilling prescriptions, or clinical problems avoidable by changing prescription medications. In managed care facilities, a pharmacist's management of chronic disease states allows an increase in interval between patient visits to physicians. In addition, responsible drug selection by pharmacists can minimize the expense of unnecessary, duplicative, or excessive pharmacotherapy to the health care system. In these situations, pharmacist prescribing can only be justified if quality of care is maintained or improved.

All pharmacists possess extensive knowledge of drug products, indications, and adverse effects. However, few pharmacists have received advanced training in physical assessment and monitoring of pharmacotherapy for positive or negative outcomes. Further, responsible prescribing requires an advanced knowledge of therapeutics. Pharmacist clinicians are not intended to serve as physician replacements, nor should they duplicate the services of nurse practitioners (NPs) or physician assistants (PAs). Instead, the rationale for the role of pharmacist clinician is expertise in drug therapy, as a "physician enhancer" who can fine-tune complex drug regimens.

\section{DEVELOPMENT OF THE PHARMACIST PRESCRIPTIVE AUTHORITY ACT}

Recognizing the potential for pharmacists to provide expanded patient-care services, the New Mexico Pharmaceutical Association (NMPhA) sought to obtain prescriptive authority for New Mexico pharmacists Through diligent lobbying efforts of its executive director, Dale Tinker, NMPhA was successful in obtaining legislative support. In April 1993, the Legislature of the State of New Mexico enacted The Pharmacist Prescriptive Authority Act, which granted prescriptive authority to pharmacist clinicians. ${ }^{1}$ The act required that these clinicians have additional training "... at least equivalent to the training received by a physician assistant." Specific regulations were required to be adopted by the Board of Pharmacy in consultation with the Board of Medical Examiners and the New Mexico Academy of Physician Assis- tants. The Board of Pharmacy has been very responsible in assuring that certified pharmacist clinicians possess the advanced skills required for prescriptive authority.

On April 18, 1995, the New Mexico Board of Pharmacy finalized four methods by which a New Mexico pharmacist can become a pharmacist clinician. Pharmacists may qualify through any one of four options':

$\Delta$ Option 1: The applicant is an actively licensed pharmacist, and has achieved national certification as a physician assistant.

$\Delta$ Option 2: Satisfactory completion of an academic curriculum that includes a minimum of sixty (60) hours of physical assessment training followed by nine (9) months of supervised clinical experience involving assessment skills.

A Option 3: Satisfactory completion of a 60-hour physical assessment course approved by the Board and a 150-hour, 300-patient contact preceptorship supervised by a physician and approved by the Board, and achievement of a passing score as defined by the Board on an appropriate examination approved by the Board.

$\boldsymbol{\Delta}$ Option 4: The applicant is certified by the Indian Health Service's Pharmacist Practitioner Program, documenta-

Continued on page 596 
tion of 600 patient contacts within the past two years as a pharmacist practitioner, accompanied by a supporting affidavit from the supervising physician.

Initially, the only examinations that have been approved for qualification under option 3 are the Board of Pharmaceutical Specialties (BPS) examinations. Pharmacist clinicians qualifying by passing the Pharmacotherapy Specialty Examination are not restricted in their scope of practice. Since other BPS examinations certify pharmacists in a more narrow scope of practice, pharmacists who qualify by passing these examinations have their practice restricted to the area certified by the specific examination.

After the pharmacist clinician is found qualified and is certified, he/she may apply for prescriptive authority by submitting protocols signed by a physician or group of physicians who agree to supervise the clinician's prescriptive authority. Protocols are a collaborative agreement between the pharmacist clinician and the supervising physician authorizing the scope of practice for the pharmacist clinician.

\section{CURRENT STATUS OF THE PHARMACIST CLINICIAN}

A physical assessment course has been developed at the University of New Mexico College of Pharmacy to assure that all doctor of pharmacy graduates qualify for certification as pharmacist clinicians under option 2 . In addition, the syllabus for this course has been"shared with community colleges, Indian Health Service facilities, and groups of pharmacists throughout the state, so that interested pharmacists may acquire the skills needed to be certified under option 3 .

Currently, two pharmacists have qualified under option 2 , based on training received in a previous post-B.S. Pharm.D. program at the University of Tennessee. The other three clinicians qualified under options 1,3 , and 4 , respectively. Four of the five clinicians had previous prescriptive authority in the Indian Health Service. Two of the clinicians are board-certified pharmacotherapy specialists. Of the five recent Pharm.D. graduates from the University of New Mexico, three are expected to apply for certification. The other two graduates are in residency training out of state. Several pharmacists throughout the state have completed the physical assessment course and are now in preceptorship training. With the lessening of rigorous standards concerning the board-approved examinations for qualifying under option 3, these pharmacists are expected to sub- mit applications for certification within the next two months.

In fall semester 1996, the University of New Mexico College of Pharmacy will offer a nontraditional Pharm.D program for alumni and pharmacists who are residents of New Mexico. While physical assessment is not a requirement of the nontraditional program, several potential nontraditional Pharm.D. students plan to complete the course to qualify for pharmacist clinician certification.

\section{CONCLUSION}

The Legislature of New Mexico has enacted a Pharmacist Prescriptive Authority Act. Board of Pharmacy regulations assure that certified pharmacist clinicians possess the advanced skills needed for rational prescribing. These regulations serve as a good model for other states considering prescriptive authority for pharmacists.

We live in an exciting time of change for the practice of pharmacy. However, we must also realize that change, albeit necessary, brings forth its own share of dangers. Expanded roles for pharmacists have evolved through intensive communications efforts with other health care professionals. We must guard against the development of pharmacist clini- cians who follow a parallel tract to physicians, analogous to PAs or NPs. This development may serve to actually decrease communication between the pharmacist and other health care professions and hinder the progression of pharmacy as a patient-care profession.

We must also realize that prescriptive authority is not essential for the practice of pharmaceutical care, although it may increase the efficiency of the pharmacist in providing pharmaceutical care. Conversely, the lack of prescriptive authority should not be used as an excuse for not providing pharmaceutical care services to our patients.

Raymond W. Hammond, Pharm.D., BCPS; Ph.C. Assistant Professor of Pharmacy Practice Experiential Programs Coordinator

Ernest J. Dole, Pharm.D. Assistant Professor of Pharmacy Practice/Geriatrics College of Pharmacy

University of New Mexico Health Sciences Center Albuquerque, NM 87131-1066

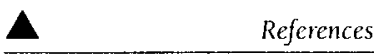

1. Section 61-1.1B-1 through 6111B-3 NMSA 1978.

2. New Mexico Board ol Pharmacy Regulation No. 4, Amendment No 4. Section 180. 